competition. However, our respondents anticipate only moderate difficulty with rivalry, and Noonan's conjecture misses the nuance that our scientists report no recent change in such competition, whereas they have seen their problems with tool exchanges increase. Moreover, in none of the 17 cases covered in our follow-up interviews was academic competition the dominant factor impeding access to a research tool.

Although we do agree with Noonan that there is a need to distinguish between 'patents' and the broader term 'intellectual property', unfortunately, he honors this distinction in the breech. Contrary to Noonan's claim, our results do not conflict with other academic reports. These focus on the direct effects of existing patents. For example, only questions $48 \mathrm{~A}-\mathrm{F}$ of the four AAAS reports ${ }^{5-8}$ ask specifically about IP protection as such. The responses, for large multidisciplinary samples of scientists in four countries, are in general remarkably supportive of our findings, though they are not discussed in any of these reports.

Thus, the paradox encountered by Noonan is resolved. Academic scientists are not greatly restricted by the need to avoid infringing existing patents because they are rarely aware of such patents and the tools they use are often too new to be patented. Even so, their work is, overall, affected indirectly by the institutional promotion of the use of MTAs, induced largely by the proliferation of patenting in academia and in industry, and this effect outweighs any incentive-related effects of patenting.

Finally, we have tried to avoid hyperbole and oversimplification in discussing this complex issue. We believe that patenting of research tools rarely 'stifles' a research project. Rather, proliferation of patenting and other IP protection of research tools has led to an increase in the use of MTAs. Resulting difficulties with research tool exchanges make the research progress of the agricultural biologists we surveyed sufficiently slower or more difficult that they believe that the costs of IP protection outweigh the benefits.

We find no reason to believe that these scientists are misinformed about these issues. It is possible that scientists fail to perceive some important social benefits from patenting their research tools. If scientists' views are surprising to some who have confused the effects of existing patents with the full implications for research of the proliferation of IP, then they are all the more valuable as a contribution to an ongoing debate.
1. Lei, Z., Juneja, R. \& Wright, B.D. Nat. Biotechnol. 27, 36-40 (2009)

2. <http://www.research.ucla.edu/mta/\#mta

3. Rodriguez, V. Nat. Biotechnol. 23, 489-491 (2005).

4. Hansen, S.A. International Intellectual Property Experiences: A Report of Four Countries (The Project on Science and Intellectual Property in the Public Interest (SIPPI), American Association for the Advancement of Science (AAAS), Washington, DC, 2007). <http://sippi.aaas.org/ Pubs/SIPPI_Four_Country_Report.pdf $>$

5. Hansen, S.A., Kisielewski, M.R. \& Asher, J.L. Intellectual Property Experiences in the United States Scientific Community (The Project on SIPPI, AAAS, Washington, DC, 2007). <http:// sippi.aaas.org/Pubs/SIPPI_US_IP_Survey.pdf>
6. Kisielewski, M.R. Asher, J.L. \& Hansen, S.A Intellectual Property Experiences in the United Kingdom Scientific Community (The Project on SIPPI, AAAS, Washington, DC, 2007). <http:// sippi.aaas.org/Pubs/SIPPI_UK_IP_Survey.pdf>

7. Westerburg, S., Asher, J.L., Kisielewski, M.R. \& Hansen, S.A. Intellectual Property Experiences in the German Scientific Community (The Project on SIPPI, AAAS, Washington, DC, 2007). <http:// sippi.aaas.org/Pubs/SIPPI_Germany_IP_Survey. pdf>

8. Walsh, J.P. \& Huang, H.I. Research Tool Access in the Age of the IP Society: Results from a Survey of Japanese Scientists (The Project on SIPPI, AAAS, Washington, DC, 2007). <http:// sippi.aaas.org/Pubs/SIPPI_Japan_IP_Survey. pdf $>$

\title{
First GM trial in Belgium since 2002
}

\section{To the Editor:}

A news article in your February issue ${ }^{1}$ reported that GM poplars developed by the group of Wout Boerjan at the Flanders Institute of Biotechnology (VIB) in Ghent were to move to the Netherlands to go on trial there. I am happy to report that VIB finally succeeded in getting an authorization for the trial in Belgium and does not have to move abroad.

The application in Belgium was first refused in May 2008, even though the Belgian Biosafety Advisory Council and the regional Flanders minister of the environment had both given their positive

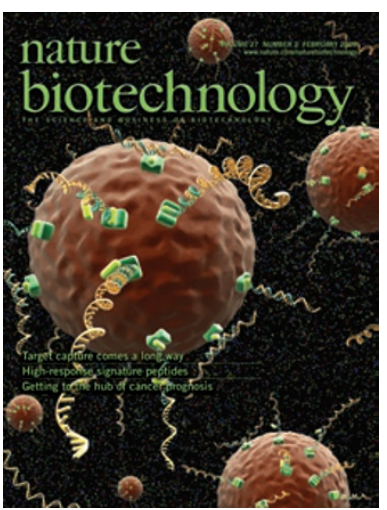

tation of the 2001/18 EU directive on the deliberate release of gentically modified organisms. Laboratory research on plant biotech, however, has always kept up its pace.

Even though VIB has successfully puradvice. VIB took legal action at the Council of State (the highest Belgian court) and made a few rounds of negotiations to overturn the negative decision and finally get the authorization in mid-February 2009.

The authorization is a landmark in the genetically modified organism field trial history in Belgium. It is the first field trial in Belgium since 2002. From 1987 to 2002 Belgium had a flourishing field trial culture reflecting the country's advanced research in plant biotech. In 1983, researchers in Ghent led by Marc Van Montagu and Jef Schell were the first to develop a genetically engineered plant. The trial in 1987 was one of the first in the world, but after 2002, the number of field trials dropped down to zero as the result of regulatory uncertainty surrounding the implemen- sued a field trial permit in The Netherlands as well, it will not start a trial there in the near future. It commenced planting of its trees last month on a field trial plot in Ghent. The plot is close to the research facilities and also close to the biofuels pilot plant, which is being set up in the port of Ghent. In trees themselves lignin biosynthesis is suppressed leading to trees with about $20 \%$ less liginin and $17 \%$ more cellulose per gram of wood. This makes them more suitable for bioethanol production. Wood from these trees grown in the greenhouse produces up to $50 \%$ more bioethanol than ordinary poplar trees. The field trial is the ultimate test to see whether wood produced under reallife conditions-seasons, stormy weather and a marginal soil-is also able to produce ethanol in a much more efficient way. VIB expects to have its first results from the trial in 2012 .

\section{René Custers}

VIB, Ghent, Belgium.

e-mail:rene.custers@vib.be

1. Birch, H. Nat. Biotechnol. 27, 107 (2009). 